\title{
ANÁLISE ERGONÔMICA NA COOPERATIVA DE CATADORES DE MATERIAIS RECICLÁVEIS NO MUNÍCIPIO DE PRESIDENTE PRUDENTE -
} SP.

\section{ERGONOMIC ANALYSIS IN THE COOPERATIVE OF RECYCLABLE MATERIALS COLECTORS IN THE MUNICIPALITY OF PRESIDENTE PRUDENTE - SP.}

Nayara de Jesus Figueiredo, Carolina Sales Ximenes; Elson Mendonça Felici; Hugo Ichikawa de Campos; Rafael Henrique Garcez Nicolau

Universidade do Oeste Paulista - UNOESTE, Engenharia Ambiental e Sanitária, Presidente Prudente, SP.

e-mail: nayarajfigueiredo@hotmail.com

RESUMO - A lei 12.305/2010 passou a considerar cooperativas de reciclagem como forma ambientalmente correta de destinação de resíduos recicláveis, diante disso o número de cooperativas vem crescendo gradativamente. A Cooperativa de Catadores de Presidente Prudente surgiu em 2003 com menos de 15 funcionários, atualmente são 90 cooperados responsáveis pela reciclagem de todos os resíduos do município. Inerentes às atividades de reciclagem dos resíduos sólidos há riscos físicos, químicos, biológicos, ergonômicos e de acidentes, no caso da COOPERLIX, riscos são grandes pois as etapas do processo de reciclagem são manuais, exigindo grande esforço físico dos cooperados e geram ocasiões de estresse devido a monotonia. Somado a isto, as condições do local mostraram-se com irregularidades, aumentando os riscos para funcionários. Dessa forma, o objetivo da presente pesquisa foi elaborar um mapa de riscos com base nas observações realizadas no local e então propor algumas possíveis melhorias.

Palavras-chave: Cooperativas. Reciclagem. Irregularidades. Riscos Ergonômicos. Mapa de riscos.

ABSTRACT - Law 12,305 / 2010 came to consider recycling cooperatives as an environmentally correct way of disposing of recyclable waste, and the number of cooperatives has gradually increased. The Presidente Prudente Waste Collection Cooperative was founded in 2003 with less than 15 employees, currently 90 cooperatives are responsible for recycling all municipal waste. In the case of COOPERLIX, there are physical, chemical, biological, ergonomic and accident hazards inherent to the solid waste recycling activities, since the steps in the recycling process are manual, requiring great physical effort by the cooperative and generating stress due to monotony. Added to this, the conditions of the place were presented with irregularities, increasing the risks for employees. Thus, the objective of the present research was to draw up a risk map based on observations made on the spot and then propose some possible improvements.

Keywords: Cooperatives. Recycling. Irregularities. Ergonomic Risks. Risk Map. 


\section{INTRODUÇÃO}

A saúde e segurança no trabalho consiste na promoção e manutenção do bem-estar físico, mental e social dos trabalhadores de todos setores das atividades, prevenção de riscos e perigos. Para serem bem-sucedidas, as medidas de saúde e de segurança no trabalho, exigem a colaboração e a participação tanto de empregadores como dos trabalhadores nos programas de saúde e segurança, obrigando a equacionar questões relacionadas com a medicina do trabalho, a higiene no trabalho, a toxicologia, a educação, a formação, a engenharia de segurança, ergonomia, psicologia, etc.

As condições deficientes podem igualmente afetar 0 ambiente onde os trabalhadores vivem, sujeitando-os a perigos inerentes às condições de trabalho não seguras e saudáveis, isso certamente traz consequências graves para os trabalhadores, para as suas famílias e para outras pessoas da comunidade.

$O$ trabalho desempenha um papel fulcral nas vidas das pessoas, considerando que a maioria dos trabalhadores passa pelo menos oito horas por dia no local de trabalho, quer seja numa plantação, num escritório, numa fábrica, etc. Desta forma, os ambientes laborais devem ser seguros e saudáveis, porém infelizmente não é essa a realidade de muitos trabalhadores. No Brasil uma das principais atividades que apresenta riscos à saúde dos trabalhadores são referentes à coleta de resíduos, por muitos anos muitas pessoas tiravam seu sustendo em "lixões" e ali exerciam suas atividades de trabalho, coletando materiais passíveis de reaproveitamento.

Atualmente com a Política Nacional de Resíduos Sólidos que determina o fechamento dos lixões, muitos trabalhadores que viviam nesses locais estão se unindo e formando as Cooperativas de Materiais Recicláveis, embora as Cooperativas apresentem melhores condições de trabalho, em comparação com os "lixões", há a necessidade de incentivo à essa classe de trabalhadores que ainda são muito desvalorizados pela sociedade e poder público.

Dessa forma, justifica-se a presente pesquisa para analisar as condições de saúde e segurança do trabalho no qual cerca de 90 cooperados estão inseridos na COOPERLIX em Presidente Prudente.

\section{METODOLOGIA}

Foi realizado uma visita na COOPERLIX de Presidente Prudente no dia 17 de maio de 2018 no período da manhã. Para verificar as condições ambientais e organizacionais de trabalho realizou-se análises visuais e registros fotográficos e os riscos foram levantados através de observações das atividades realizadas. Para a identificação e classificação dos riscos no local de estudo utilizou-se como base a Norma Regulamentado $\mathrm{N}^{\circ} 9$ do Ministério do Trabalho e Emprego que tem como objetivo a preservação da saúde dos colaboradores através da avaliação e controle dos riscos ambientais e classifica os riscos em físico, químico e biológico. No presente trabalho considerou-se ainda os riscos ergonômicos e de acidentes, pois são riscos que devem ser considerados durante a elaboração do mapa de riscos da empresa. Com o auxílio do programa COREL DRAW e com base na NR 5 , item 5-16 alínea "o", elaborou-se um mapa de riscos que consiste em uma representação gráfica dos riscos de acidentes nos diversos locais de trabalho, a criação do mesmo torna-se fundamental pois pode ser um aliado para encontrar soluções práticas que visam eliminar ou controlar riscos e melhorar o ambiente, as condições de trabalho e a produtividade. Com base nos riscos encontrados elaborou-se ainda uma tabela com propostas de melhorias para a COOPERLIX.

\section{RESULTADOS}

\subsection{Descrição do local}

Localizada no Distrito Industrial em Presidente Prudente - SP, a Cooperlix (Cooperativa de Trabalhadores de Produtos Recicláveis de Presidente Prudente) foi fundada no ano de 2003. O primeiro bairro a ser implantado o serviço foi o Conjunto Habitacional Ana Jacinta e posteriormente foi expandido para outros bairros, atualmente a Cooperlix conta com 90 cooperados, com idade entre 21 e 64 anos, que tem como fonte de renda e sobrevivência a coleta e venda de materiais recicláveis.

O funcionamento da cooperlix segue o estatuto das cooperativas, a renda arrecadada é dividida entre seus associados e parte é destinado ao fundo de reserva, este serve para reparar perdas e atender ao desenvolvimento de suas atividades. A jornada de trabalho na COOPERLIX inicia-se por volta das 7:40 horas e 
encerra-se às 17:00 horas, com pausa de uma hora para almoço e cerca de meia hora para o café da tarde.

\subsection{Entradas e saídas}

A coleta dos materiais recicláveis é realizada por um caminhão que foi concedido pela prefeitura de Presidente Prudente, este chega à COOPERLIX e descarrega os materiais em um local totalmente aberto, expondo os funcionários às variações do clima. Neste momento, cerca de três funcionários realizam a retirada do material de dentro do caminhão e são responsáveis de encaminha-los até o funil.

Figura 1: Chegada dos materiais recicláveis na Cooperativa de Catadores.

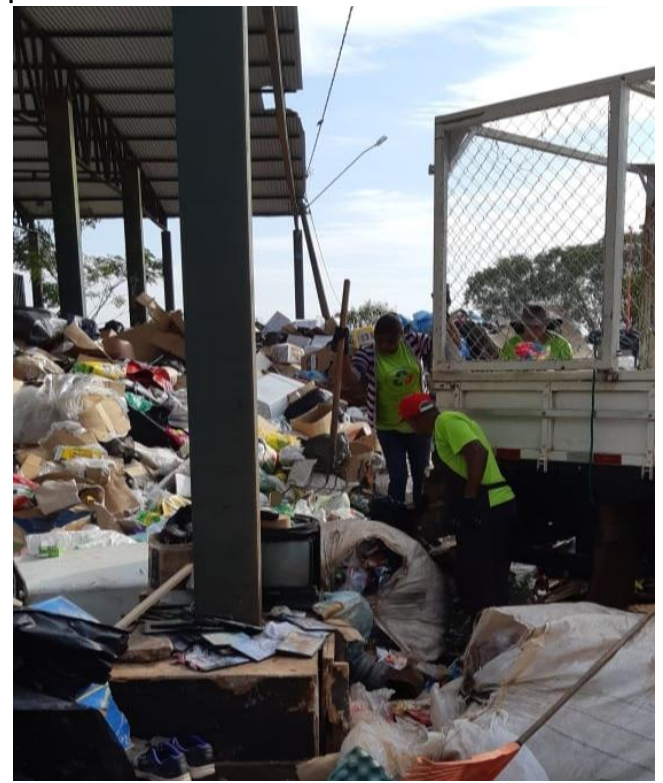

Fonte: Autores (2018).

Após passar pelo funil os materiais chegam na esteira, como é uma etapa menos sobrecarregada, somente mulheres ficam neste local. Essas funcionárias realizam a triagem do material e coloca-os em seus respectivos sacos "BAGS", os materiais são separados de acordo com sua natureza: Plástico, papel, vidro, papelão, eletrônicos, metal, etc.

Para a prensagem dos materiais há duas máquinas no local, uma automática que realiza a prensagem dos papelões e outra mecânica que prensa materiais plásticos. Essa última exige um esforço manual superior à prensa automática, e gera um ruído extremamente alto.

Após a prensagem dos materiais, uma empilhadeira é responsável por leva-los até ao armazém ao lado do balcão, ali eles ficam acondicionados até que as empresas que compram os materiais recicláveis compareçam ao local para a retirada dos mesmos. Ferros, alumínio, cobre e outros produtos que apresentam riscos são encaminhados a outro setor, os cooperados neste local separam esses materiais para posteriormente vende-los.

A limpeza do local ocorre antes do almoço e após o café da tarde, com exceção da prensagem que a todo momento há necessidade de varrição do local.

Figura 2 e 3: Fase da prensagem de alguns tipos de materiais.

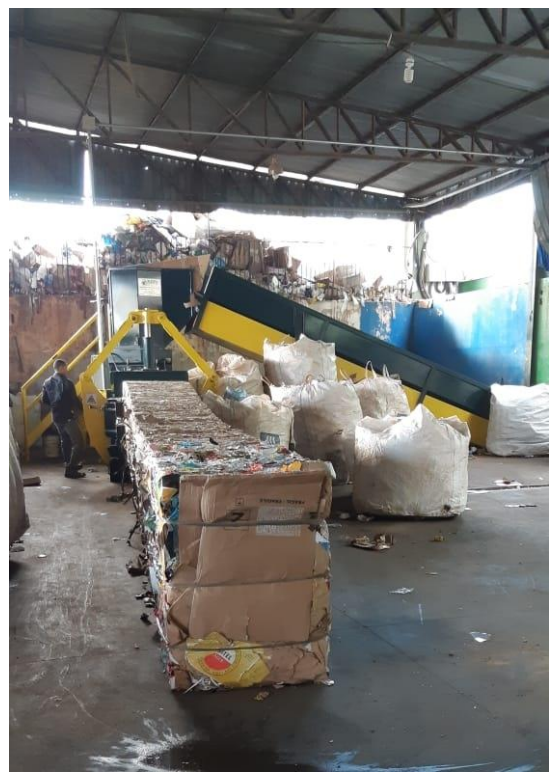

Fonte: Os autores (2018).

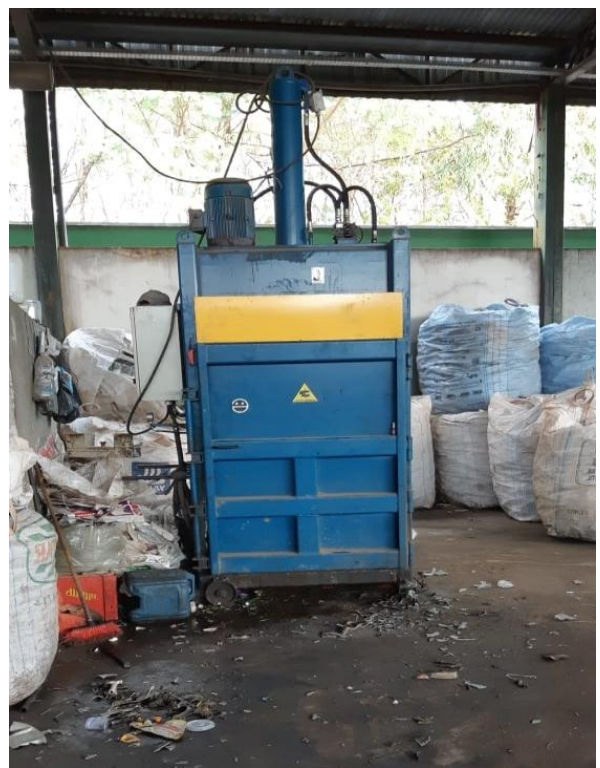

Fonte: Os autores (2018).

Após a prensagem dos materiais, uma empilhadeira é responsável por leva-los até ao armazém ao lado do balcão, ali eles ficam acondicionados até que as empresas que 
compram os materiais recicláveis compareçam ao local para a retirada dos mesmos. Ferros, alumínio, cobre e outros produtos que apresentam riscos são encaminhados a outro setor, os cooperados neste local separam esses materiais para posteriormente vende-los.

A limpeza do local ocorre antes do almoço e após o café da tarde, com exceção da prensagem que a todo momento há necessidade de varrição do local.

\subsection{Levantamento de Riscos}

Com base nas análises visuais de todo o processo da reciclagem dos materiais e das condições de trabalho no qual os cooperados estão inseridos, identificou-se e classificou-se os riscos em ergonômico, acidente, químico, físico e biológico. Após a identificação dos riscos, gerouse a seguinte tabela:

Tabela 1. Levantamento dos riscos, classificação e propostas para melhorias no ambiente de trabalho na Cooperativa de Materiais Recicláveis.

\begin{tabular}{|c|c|c|c|c|}
\hline Atividadel Etapa & Riscos & $\begin{array}{c}\text { Classificaçãa } \\
\text { o }\end{array}$ & Prazo & Proposta \\
\hline $\begin{array}{c}\text { Chegada } \\
\text { (descarregamento) }\end{array}$ & $\begin{array}{l}\text {-Esforço fisico } \\
\text {-Acidente trânsito } \\
\text {-Poeira } \\
\text {-Materiais Cortantes } \\
\text {-Animais peçonhentos }\end{array}$ & $\begin{array}{l}\text {-Ergonomico } \\
\text {-Acidente } \\
\text {-Químico } \\
\text {-Acidente } \\
\text {-Biológico }\end{array}$ & $\begin{array}{l}\text {-Longo } \\
\text {-Curto } \\
\text {-Longo } \\
\text {-Longo } \\
\text {-Médio }\end{array}$ & $\begin{array}{l}\text {-Ginastica Laboral } \\
\text {-Manutenção dos } \\
\text { veículos } \\
\text {-Uso de EPI } \\
\text {-Uso de EPI }\end{array}$ \\
\hline Triagem & $\begin{array}{l}\text {-Materiais cortantes } \\
\text {-Esforço físico } \\
\text { repetitivo }\end{array}$ & $\begin{array}{l}\text {-Acidente } \\
\text {-Ergonómico }\end{array}$ & $\begin{array}{l}\text {-Longo } \\
\text {-Médio }\end{array}$ & $\begin{array}{l}\text {-Uso de EPI } \\
\text {-Revezamento de } \\
\text { funçóes }\end{array}$ \\
\hline Prensagem & $\begin{array}{l}\text {-Ruidos } \\
\text {-Contato com } \\
\text { máquina }\end{array}$ & $\begin{array}{l}\text {-Fisico } \\
\text {-Acidente }\end{array}$ & $\begin{array}{l}\text {-Longo } \\
\text {-Curto }\end{array}$ & $\begin{array}{l}\text {-Uso de EPI } \\
\text {-Treinamento }\end{array}$ \\
\hline Pesagem & -Esforço fisico & -Acidente & -Longo & $\begin{array}{l}\text {-Revezamento de } \\
\text { funçóes } \\
\text {-Utilizar } \\
\text { maquinário }\end{array}$ \\
\hline Empilhadeira & $\begin{array}{l}\text {-Atropelamento } \\
\text {-Esforço repetitivo }\end{array}$ & $\begin{array}{l}\text {-Acidente } \\
\text {-Ergonómico }\end{array}$ & $\begin{array}{l}\text {-Medio } \\
\text {-Curto }\end{array}$ & $\begin{array}{l}\text {-Sinalizaçáo } \\
\text {-Revezamento }\end{array}$ \\
\hline $\begin{array}{c}\text { Separaçäo } \\
\text { (Aluminio e Cobre) }\end{array}$ & $\begin{array}{l}\text {-Fagulhas } \\
\text {-Objetos Cortantes } \\
\text {-Esforço físico } \\
\text {-Incêndio }\end{array}$ & $\begin{array}{l}\text {-Fisico } \\
\text {-Acidente } \\
\text {-Ergonómico } \\
\text {-Acidente }\end{array}$ & $\begin{array}{l}\text {-Longo } \\
\text {-Longo } \\
\text {-Médio } \\
\text {-Curto }\end{array}$ & $\begin{array}{l}\text {-Uso de EPI } \\
\text {-Uso de EPI } \\
\text {-Revezamento } \\
\text {-Extintores }\end{array}$ \\
\hline RH (Escritório) & -Postura inadequada & -Ergonómico & -Curto & $\begin{array}{l}\text {-Adequaçáo de } \\
\text { equipamentos }\end{array}$ \\
\hline Limpeza & $\begin{array}{l}\text {-Esforço } \\
\text {-Chăo escorregadio }\end{array}$ & $\begin{array}{l}\text {-Ergonómico } \\
\text {-Acidente }\end{array}$ & $\begin{array}{l}\text {-Curto } \\
\text {-Curto }\end{array}$ & $\begin{array}{l}\text {-Atividade laboral } \\
\text {-Sinalização }\end{array}$ \\
\hline- & -lluminação precária & $\begin{array}{l}\text {-Fisico } \\
\text {-Ergonómico }\end{array}$ & -Curto & $\begin{array}{l}\text {-Adequaçáo da } \\
\text { parte elétrica }\end{array}$ \\
\hline
\end{tabular}

Fonte: Os autores (2018).

\subsubsection{Ergonômico}

São considerados riscos ergonômicos aqueles que estão ligados ao esforço físico, levantamento de peso, postura inadequada, monotonia e repetitividade, dentre outros. Podese dizer que em todas as etapas de trabalho na COOPERLIX há riscos ergonômicos, por muito tempos a Cooperativa não forneceu treinamento quanto a saúde no trabalho, de acordo com um funcionário do local faz 4 meses que montou a CIPA (Comissão Interna de Prevenção de Prevenção de Acidentes), desde então os cooperados passaram em médicos e um técnico social ministrou uma palestra sobre os riscos em que os funcionários estão expostos. Embora os cooperados não tenham carteira assinada eles contribuem com a previdência social. 


\subsubsection{Físico}

Os riscos físicos estão relacionados com as condições do ambiente de trabalho, estes se apresentam em forma de ruídos, temperaturas extremas, vibrações, radiações ionizantes, frio, calor, umidade etc. Na COOPERLIX um dos principais riscos físicos se refere à iluminação do local, embora haja presença de luz natural, em dias nublados o local possui uma iluminação fraca e não há lâmpadas que funcionem pois estas estão queimadas devido a irregularidade na parte elétrica. Os cooperados responsáveis pela retirada dos materiais do caminhão ficam expostos a chuvas e grande radiação solar, pois não há cobertura na etapa de descarregamento. Na fase de prensagem, há uma geração média de ruídos e todos os funcionários que ficam no galpão estão submetidos a estes ruídos.

\subsubsection{Biológico}

Os riscos biológicos se referem a exposição de vírus, bactérias, parasitas, protozoários, fungos e bacilos, ou qualquer outro risco que ocorrem por meio de microrganismos, este em contato com o homem, podem provocar inúmeras doenças. Devido a atividade que os cooperados exercem há grandes riscos biológicos, pois infelizmente a população ainda mistura resíduos hospitalares com os materiais recicláveis, funcionários do local relatam que já houve casos de contato com agulhas de insulina. A cooperativa de Presidente Prudente se localiza em um local isolado, muitos animais peçonhentos já foram encontrados, como escorpiões, cobras, ratos, baratas etc., o que representa riscos biológicos a todos que ali trabalham.

\subsubsection{Acidentes}

Quanto aos riscos de acidentes são: qualquer fator que coloque o trabalhador em situação vulnerável e possa afetar sua integridade, e seu bem-estar físico e psíquico. São exemplos de risco de acidentes: as máquinas e equipamentos sem proteção, probabilidade de incêndio e explosão, arranjo físico inadequado, armazenamento inadequado, etc. Durante a visita à COOPERLIX não encontramos extintores de incêndio, submetendo o local a riscos de incêndio e não há também qualquer tipo de sinalização dentro ou fora do galpão, quanto ao uso de equipamentos de proteção individual os cooperados utilizam óculos, protetor auricular, luvas, máscaras e botas.

\subsubsection{Químicos}

Os riscos químicos são substâncias, compostos ou produtos que possam penetrar no organismo do trabalhador pela via respiratória. $\mathrm{Na}$ COOPERLIX identificou-se somente a poeira e emissão de gases no processo de descarregamento.

\subsection{Mapa de Riscos}

O mapa de riscos permite a identificação de pontos vulneráveis na planta de determinado local, por meio de cores e círculos de tamanhos diferentes há a representação de ambientes e fatores que podem gerar situações de perigo pela presença de agentes físicos, químicos, biológicos, ergonômicos e mecânicos (acidentes).

O mapa de risco abaixo foi obtido com base nas observações, conversas informais com cooperados, classificação e análises de riscos, tais análises contribuem para diversos programas no combate a acidentes e doenças de trabalho.

Figura 4. Mapa de riscos da COOPERLIX.
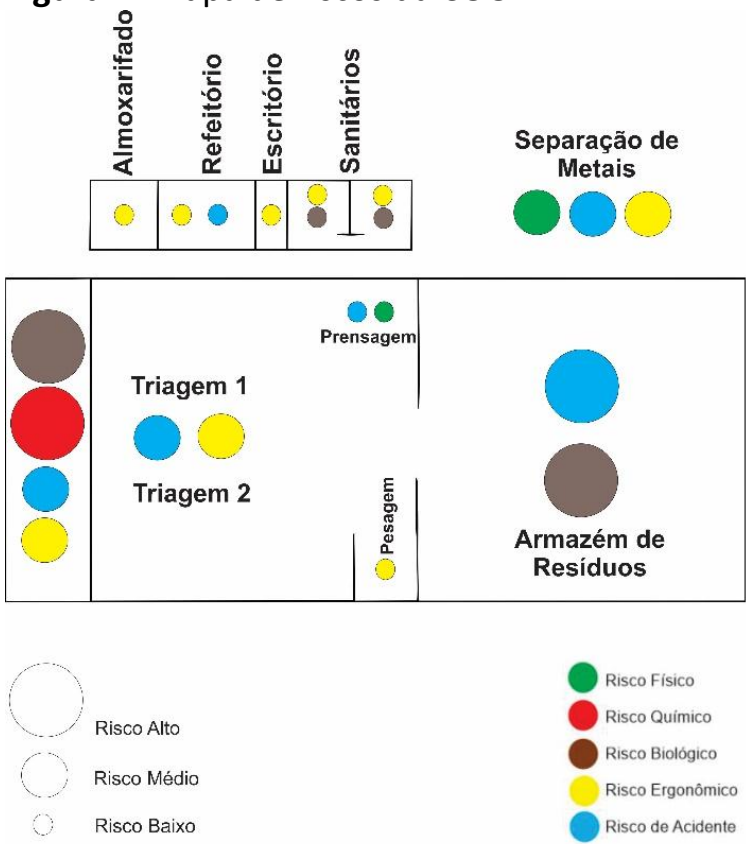

Fonte: Os autores (2018).

\section{DISCUSSÃO}

O trabalho exercido na Cooperativa de Presidente Prudente demonstrou-se bastante árduo, pois, exigem que os cooperados fiquem em pé a maior parte do tempo, segundo a NBR 17, sempre que possível, o trabalho deve ser executado na posição sentada, caso isso não ocorra, a norma estabelece que as bancadas devem ter altura e características reajustadas de 
acordo com a necessidade dos funcionários, isso certamente irá facilitar a movimentação e ajustará o posicionamento daqueles que trabalham no local.

Segundo uma análise feita na Cooperativa de Materiais Recicláveis da região Metropolitana de Curitiba - PR, os riscos encontrados foram similares, em ambos estudos se observou que as atividades realizadas em cooperativas sofrem indiferenças por parte do poder público, comprova-se isso através do ambiente em que os cooperados exercem suas funções, falta de incentivo público e valorização da reciclagem no Brasil reflete nas condições de trabalho e consequentemente aumenta os riscos no qual estão inseridos.

Durante o levantamento de riscos, o risco ergonômico esteve presente em grande parte das etapas analisadas, isso explica-se devido ao fato de que a triagem e separação dos materiais recicláveis são manuais, o que exige esforço repetitivo daqueles que trabalham no local.

LIMA e SILVA (2017) realizou uma pesquisa na etapa de triagem dos materiais recicláveis em uma cooperativa de catadores em Londrina-PR, onde constatou-se a necessidade de investir na capacitação dos cooperados, isso se confirma também no presente estudo, todas as pessoas que exercem atividades na cooperativa viviam anteriormente na informalidade, com baixo grau de escolaridade e sem conhecimento quanto a saúde e segurança do trabalho.

\section{CONSIDERAÇÕES FINAIS}

Verificou-se através do levantamento de riscos na cooperativa, a presença dos cinco tipos de riscos no local, sendo alguns de alta magnitude. Embora a Prefeitura de Presidente Prudente já ofereça um incentivo para a Cooperativa por meio de um contrato que propicia transporte, equipamentos de proteção individual e alimentação, há a necessidade de realizar melhorias nas condições de trabalho da cooperativa de reciclagem.

Além das ações relacionadas a segurança do trabalho, entende-se ser indispensável o fornecimento de cursos de capacitação em reciclagem que garanta em sua totalidade os direitos trabalhistas dos cooperados e o favorecimento da alfabetização dos funcionários do local.

\section{REFERÊNCIAS}

CIPA. Mapa de riscos do trabalho. Disponível em: <http://cipa.fmrp.usp.br/Html/MapaRisco.htm> Acesso em 20 de Maio de 2018.

INBEP. 4 Passos Fundamentais para realizar a análise de riscos. Disponível em $<$ http://blog.inbep.com.br/4-passos-

fundamentais-para-realizar-a-analise-dos-riscos/> Acesso em 23 de Maio de 2018.

LIMA, C.H; SILVA A.L. Análise ergonômica na etapa de triagem de materiais em uma cooperativa de catadores de materiais recicláveis em Londrina-PR. VI Congresso de Engenharia de Produção. Ponta Grossa - PR, Brasil. 6 a 8 de dezembro de 2017.

\section{NR 5. Comissão Interna De Prevenção De} Acidentes - CIPA. Disponível em: <http://www.guiatrabalhista.com.br/legislacao/n r/nr5.htm> Acesso em 20 de Maio de 2018.

NR 9. Programa de Prevenção de Riscos Ambientais. Disponível em < http://www.guiatrabalhista.com.br/legislacao/nr /nr9.htm > Acesso em 20 de Maio de 2018.

NR 17. Ergonomia. Disponível em < http://www.trt02.gov.br/geral/tribunal2/LEGIS/C LT/NRs/NR_17.html > Acesso em 20 de Maio de 2018.

SEGPLAN. Gerência de Saúde e Prevenção da Superintendência Central de Recursos Humanos. Manual de Elaboração de Mapa de Risco. Goiás. Disponível em: <http://www.sgc.goias.gov.br/upload/arquivos/2 012-11/manual-de-elaboracao-de-maparisco.pdf> Acesso em 20 de Maio de 2018.

SST. Riscos Ambientais. Disponível em $<$ https://areasst.com/riscos-ambientais/> Acesso em 20 de Maio de 2018.

TROMBETA, L.R. O Trabalho Dos Catadores De Materiais Recicláveis: Da Precarização À Organização Do Trabalho. Disponível em $<$ http://revista.fct.unesp.br/index.php/pegada/ar ticle/view/1083/1895> Acesso em 20 de Maio de 2018. 
WEDDERHOFF, S. Análise ergonômica em uma cooperativa de catadores de materiais recicláveis de um município da região metropolitana de Curitiba. Universidade Federal do Paraná 2012. 